\title{
INFLUÊNCIA DA TEMPERATURA, PERÍODO DE MOLHAMENTO E CONCENTRAÇÃO DO INÓCULO DE FUNGOS NA INCIDÊNCIA DE PODRIDÕES PÓS-COLHEITA EM FRUTOS DE TOMATEIRO*
}

\author{
NORMA S.S. SILVEIRA ${ }^{1}$, SAMI J. MICHEREFF ${ }^{2 * *}$, ROSA L.R. MARIANO ${ }^{2 * *}$, LUCIANA A. TAVARES $^{2}$ \& \\ LEONOR C. MAIA ${ }^{3}$
}

\begin{abstract}
'Departamento de Botânica, Universidade Federal de Alagoas, CEP 57010-020, Maceió, AL, Fax (82) 221-2501;
${ }^{2}$ Área de Fitossanidade, Departamento de Agronomia, Universidade Federal Rural de Pernambuco, CEP 52171-900, Recife, PE, Fax: (81) 441-1711, e-mail: michereff@uol.com.br; ${ }^{3}$ Departamento de Micologia, Universidade Federal de Pernambuco, CEP 50670-420, Recife, PE
\end{abstract}

(Aceito para publicação em 09/11/2000)

Autor para correspondência: Sami J. Michereff

SILVEIRA, N.S.S., MICHEREFF, S.J., MARIANO, R.L.R., TAVARES, L.A. \& MAIA, L.C. Influência da temperatura, período de molhamento e concentração do inóculo de fungos na incidência de podridões pós-colheita em frutos de tomateiro. Fitopatologia Brasileira 26:33-38. 2001.

\section{RESUMO}

Foi avaliada a influência da temperatura $(5,15,25$ e $\left.35{ }^{\circ} \mathrm{C}\right)$, da duração do período de molhamento $(0,3,6,12$, 24,48 e 72 h) e da concentração de inóculo $\left(10^{1}, 10^{2}, 10^{4}\right.$, $10^{6}$ e $10^{8}$ esporos $/ \mathrm{ml}$ ) na incidência de podridões de póscolheita em frutos de tomateiro (Lycopersicon esculentum) (cv. Santa Clara) causadas por Fusarium verticillioides, Geotrichum candidum e Rhizopus stolonifer. A temperatura influenciou significativamente $(\mathrm{P}=0,05)$ a incidência de podridões, ocorrendo maior incidência de lesões em frutos incubados a $25^{\circ} \mathrm{C}$. Não foi observado o desenvolvimento de podridão em frutos inoculados com $F$. verticillioides e incubados nas temperaturas de 5 e $35^{\circ} \mathrm{C}$, sendo nesta última verificada a menor incidência de podridões causadas por G. candidum e R. stolonifer. Nas temperaturas de 5, 15 e $25{ }^{\circ} \mathrm{C}$, a incidência de podridões causadas por $R$. stolonifer variou entre 97,5 e $100 \%$. A presença de água livre na superfície dos frutos de tomateiro foi desnecessária para a incidência de podridões causadas por $F$. verticillioides, $G$. candidum e $R$. stolonifer, embora os níveis de incidência tenham aumentado com o incremento no período de molhamento, exceto para $R$. stolonifer, que causou a incidência máxima de doença $(100 \%)$, na ausência de molhamento. A incidência de podridões aumentou com o incremento na concentração de inóculo de $10^{1}$ a $10^{8}$ esporos $/ \mathrm{mL}$, atingindo o máximo (100\%) na concentração de $10^{4}$ esporos $/ \mathrm{ml}$ para $F$. verticillioides e $R$. stolonifer, enquanto o mesmo nível foi atingido por G. candidum com $10^{8}$ esporos $/ \mathrm{ml}$.

Palavras-chave: doenças pós-colheita, Lycopersicon esculentum, Fusarium verticillioides, Geotrichum candidum, Rhizopus stolonifer.

\section{ABSTRACT \\ Influence of temperature, wetness period and fungal inoculum concentration on incidence of post-harvest tomato fruit rots}

The influence of temperature was studied $(5,15,25$ and $\left.35^{\circ} \mathrm{C}\right)$, wetness period $(0,3,6,12,24,48$ and $72 \mathrm{~h})$ and inoculum concentration $\left(10^{1}, 10^{2}, 10^{4}, 10^{6}\right.$ and $10^{8}$ spores $/ \mathrm{ml}$ ) on the intensity of post-harvest rots in tomato (Lycopersicon esculentum) fruits (cv. Santa Clara) caused by Fusarium verticillioides, Geotrichum candidum and Rhizopus stolonifer. Temperature significantly influenced $(\mathrm{P}=0,05)$ rot incidence. Higher incidence of lesions was observed when fruit were incubated at $25{ }^{\circ} \mathrm{C}$. Disease development was not observed in fruit inoculated with $F$.

\footnotetext{
*Parte da Tese de Doutorado do primeiro autor apresentada ao Programa de Pós-graduação em Botânica da Universidade Federal Rural de Pernambuco (1999).

**Bolsista do CNPq.
}

verticillioides and incubated at 5 and $35{ }^{\circ} \mathrm{C}$. The smallest incidences of $G$. candidum and $R$. stolonifer rots were verified at $35{ }^{\circ} \mathrm{C}$. The incidence of $R$. stolonifer rot was very high at 5,15 and $25{ }^{\circ} \mathrm{C}$, varying between 97.5 and $100 \%$. The presence of free water on the surface of tomato fruit was not necessary for the incidence of $F$. verticillioides, $G$. candidum and $R$. stolonifer rots. However, disease incidence levels increased with the increment in the wetness period, except for $R$. stolonifer that caused $100 \%$ disease incidence even in absence of free water. The incidence of tomato fruit rots increased with the increment of the inoculum concentration from $10^{1}$ to $10^{8}$ spores. $\mathrm{ml}^{-1}$. It reached $100 \%$ at $10^{4}$ spores. $\mathrm{ml}^{-1}$ for $F$. verticillioides and $R$. stolonifer, and $10^{8}$ spores. $\mathrm{mL}^{-1}$ for G. candidum. 


\section{INTRODUÇÃO}

Doenças fúngicas causam consideráveis perdas póscolheita em frutos de tomateiro (Lycopersicon esculentum Mill.) (Arinze, 1986; Ceponis et al., 1986), podendo atingir até $20 \%$ na fase de comercialização (Onesirosan \& Fatunla, 1979). Essas doenças são causadas principalmente por fungos encontrados nos ambientes de seleção e embalagem, locais de transporte e armazenamento dos frutos (Ceponis \& Butterfield, 1979). Espécies do gênero Fusarium Link.:Fr., Geotrichum candidum Link. ex Pers. eRhizopus stolonifer (Ehrenb.:Fr.) Vuill. têm sido relatadas como predominantes entre os agentes de doenças pós-colheita em frutos de tomateiro, principalmente em regiões tropicais durante a fase de comercialização (Arinze, 1986; Olandiran \& Iwu, 1993). Esses patógenos requerem ferimentos para penetração no hospedeiro e causam perdas quantitativas importantes ao induzirem o aparecimento de lesões de evolução rápida e que resultam no apodrecimento completo dos frutos (Lopes \& Santos, 1994; O'Brien et al., 1994).

A frequiência e a intensidade da doença são significativamente influenciadas pelo grau de desvio de cada condição ambiental do ponto no qual o progresso da doença é máximo. A temperatura e a umidade na superfície da planta são os fatores ambientais que afetam mais intensamente o início e o progresso de doenças infecciosas em plantas. Os patógenos diferem em suas preferências por alta ou baixa temperatura, uma vez que a mesma afeta a germinação de esporos e o número de esporos formados. A umidade, por sua vez, é indispensável para a germinação da maioria dos esporos fúngicos e para a penetração do tubo germinativo no hospedeiro, além de aumentar a suscetibilidade a certos patógenos, afetando a incidência e a severidade da doença (Agrios, 1997). Em relação à pós-colheita em frutos de tomateiro, a temperatura e a umidade afetam significativamente o tempo de vida dos frutos e, especialmente, a taxa de deterioração por microrganismos (Arinze, 1986).

Reduzido número de estudos sobre a epidemiologia de doenças em frutos de tomateiro têm sido realizados, destacandose os trabalhos com Botrytis cinerea Pers.:Fr. (Eden et al., 1996), Colletotrichum coccodes (Wallr.) Hugh. (Dillard, 1989; Sanogo et al., 1997), Fusarium spp. e R. stolonifer (Arinze, 1986), motivo pelo qual os aspectos relacionados à influência dos fatores ambientais e da concentração de inóculo no progresso de podridões pós-colheita desses frutos ainda não foram totalmente esclarecidos.

Considerando-se a importância das podridões fúngicas no volume total de perdas pós-colheita de frutos de tomateiro, este trabalho teve como objetivo estudar a influência da temperatura, do período de molhamento e da concentração do inóculo de Fusarium verticillioides (Sacc.) Niremberg, G. candidum e R. stolonifer na incidência de podridões póscolheita em frutos de tomateiro.

\section{MATERIAL E MÉTODOS}

\section{Produção de inóculo e inoculação}

Os isolados de $F$. verticillioides (P-96), G. candidum
(P-98) e R. stolonifer (P-140) foram obtidos de frutos de tomateiro com sintomas de podridão, coletados em feiras livres da cidade de Recife, Estado de Pernambuco, Brasil (Silveira et al., 1998). A partir de culturas com cinco dias de crescimento, em placas de Petri, com meio batata-dextroseágar (BDA), incubadas a $25 \pm 2{ }^{\circ} \mathrm{C}$, sob alternância luminosa (12 h claro/12 h escuro), foram preparadas suspensões de esporos pela adição de água destilada esterilizada à superfície das culturas, filtragem em camada dupla de gaze e ajuste da concentração em hemacitômetro. As inoculações foram realizadas em frutos sadios de tomateiro, cultivar Santa Clara, no estádio de maturação vermelho (Pratt \& Workman, 1962), desinfestados superficialmente pela imersão em $\mathrm{NaClO} 0,05 \%$ por $5 \mathrm{~min}$. Em cada fruto, foram marcados quatro pontos opostos à região do pedúnculo, onde foram efetuados 10 ferimentos de aproximadamente $3 \mathrm{~mm}$ de profundidade, com o auxílio de uma almofada com alfinetes, sendo depositado 0,1 $\mathrm{ml}$ das suspensões contendo esporos dos patógenos em cada ponto. Após a inoculação, os frutos foram mantidos sobre tampas de placas de Petri contendo algodão hidrófilo umedecido com água destilada esterilizada e o conjunto foi colocado em sacos plásticos, constituindo a câmara úmida. As avaliações foram efetuadas três dias após a inoculação dos patógenos, pela análise da incidência de podridão, determinada pelo percentual de pontos inoculados apresentando lesões.

\section{Influência da temperatura na incidência das doenças}

Frutos de tomateiro foram aclimatados às temperaturas de $5,15,25$ e $35^{\circ} \mathrm{C}$, durante $5 \mathrm{~h}$ em incubadoras do tipo BOD, sob alternância luminosa. Posteriormente, esses frutos foram inoculados com os isolados de $R$. stolonifer, $F$. verticillioides e G. candidum, na concentração de $10^{6}$ esporos/ $\mathrm{ml}$. Após a inoculação, os frutos foram mantidos em câmara úmida e incubados nas mesmas temperaturas acima durante todo o período de avaliação. O delineamento experimental foi inteiramente casualizado, em arranjo fatorial $3 \times 4$, representado por três patógenos e quatro temperaturas, com 10 repetições, sendo cada repetição constituída por um fruto.

\section{Influência do período de molhamento na incidência das doenças}

Frutos de tomateiro foram inoculados com os isolados de $R$. stolonifer, F. verticillioides e G. candidum, na concentração de $10^{6}$ esporos $/ \mathrm{ml}$. Após a inoculação, os frutos foram submetidos a diferentes períodos de molhamento, pela manutenção durante $0,3,6,12,24,48$ e 72 h em câmara úmida, à temperatura de $25^{\circ} \mathrm{C}$. O delineamento experimental foi inteiramente casualizado, em arranjo fatorial $3 \times 7$, representado por três patógenos e sete períodos de molhamento, com 10 repetições, sendo cada repetição constituída por um fruto.

\section{Influência da concentração de inóculo na incidência das} doenças

Frutos de tomateiro foram inoculados com os isolados de $R$. stolonifer, F. verticillioides e G. candidum, nas 
Influência da temperatura, período de molhamento e concentração do inóculo...

concentrações de $10^{1}, 10^{2}, 10^{4}, 10^{6}$ e $10^{8}$ esporos $/ \mathrm{ml}$. Após a inoculação e a colocação em câmara úmida, os frutos foram incubados à temperatura de $25^{\circ} \mathrm{C}$. $\mathrm{O}$ delineamento experimental foi inteiramente casualizado, em arranjo fatorial $3 \times 5$, representado por três patógenos e cinco concentrações de inóculo, com 10 repetições, sendo cada repetição constituída por um fruto.

\section{Análise dos dados}

Os dados originais foram transformados em $\sqrt{x+1}$ e submetidos à análise de variância, sendo a separação de médias efetuada pelo teste de Duncan, ao nível de 5\% de probabilidade, com o auxílio do programa STATISTICA for Windows Release 5.1 (StatSoft Inc., Tulsa - OK, USA, 1996). Os dados também foram submetidos à análise de regressão linear e não-linear, para selecionar os modelos com os melhores ajustes às curvas de progresso da incidência das podridões, com base no coeficiente de determinação $\left(\mathrm{R}^{2}\right)$ e no quadrado médio do resíduo (QMR), com o auxílio do programa TableCurve ${ }^{\mathrm{TM}}$ 2D for Windows Version 4.07 (SPSS Software Inc., Chicago - IL, USA, 1998).

\section{RESULTADOS}

\section{Influência da temperatura na incidência das doenças}

A temperatura influenciou significativamente $(\mathrm{P}=0,05)$ a incidência de podridões em frutos de tomateiro causadas por $F$. verticillioides, G. candidum e $R$. stolonifer. Foram constatadas diferenças significativas $(\mathrm{P}=0,05)$ nos valores de incidência das doenças entre os fungos para as diferentes temperaturas, bem como verificada interação significativa $(\mathrm{P}=0,05)$ entre fungos e temperaturas.

Maior incidência de lesões foi observada em frutos incubados a $25^{\circ} \mathrm{C}$. Não foi observada a incidência de podridão em frutos inoculados com $F$. verticillioides e incubados nas temperaturas de 5 e $35^{\circ} \mathrm{C}$, enquanto nesta última foi verificada a menor incidência de podridões causadas por G. candidum e $R$. stolonifer. Nas temperaturas de 5,15 e $25^{\circ} \mathrm{C}$, a incidência de podridões causadas $R$. stolonifer foi muito elevada, variando entre 97,5 e $100 \%$ (Figura 1 ).

O modelo não linear $y=a+b x+c . \exp ^{x}$ proporcionou um excelente ajuste das curvas de progresso da incidência das podridões em função das temperaturas de incubação, com os coeficientes de determinação $\left(\mathrm{R}^{2}\right)$ variando entre 95,57 (G. candidum) e 99,83\% (R. stolonifer) (Figura 1).

\section{Influência do período de molhamento na incidência das doenças}

A presença de água livre na superfície dos frutos de tomateiro, na forma de condensação, não foi necessária para a incidência de podridões causadas por $F$. verticillioides, $G$. candidum e $R$. stolonifer, embora os níveis de incidência tenham aumentado com o incremento no período de molhamento, exceto para $R$. stolonifer, que causou a incidência máxima de doença (100\%), mesmo na ausência de molhamento (Figura 2).
Foram constatadas diferenças significativas $(\mathrm{P}=0,05)$ nos valores de incidência das doenças entre os fungos para os diferentes períodos de molhamento, bem como verificada interação significativa $(\mathrm{P}=0,05)$ entre fungos e períodos de molhamento.

Um período de $24 \mathrm{~h}$ de molhamento permitiu que os frutos inoculados com $F$. verticillioides atingissem $100 \%$ de incidência, enquanto os inoculados com G. candidum atingiram o nível máximo de $95 \%$ com 48 h de molhamento.

O modelo não linear Logístico Dose-Resposta $y=a+b /$ $\left(1+(x / c)^{d}\right)$ proporcionou um excelente ajuste das curvas de progresso da incidência das podridões em função dos períodos de molhamento, com coeficientes de determinação de 99,01 e $99,88 \%$, respectivamente para $F$. verticillioides $[\mathrm{y}=$ $10,20+93,94 /\left(1+(\mathrm{x} / 2,97)^{-1,19}\right]$ e $G$. candidum $[\mathrm{y}=56,90+2,26 /$ $\left(1+(\mathrm{x} /-0,04)^{-0,0003}\right]$ (Figura 2$)$.

\section{Influência da concentração de inóculo na incidência das doenças}

A incidência de podridões em frutos de tomateiro aumentou com o incremento na concentração de inóculo de $10^{1}$ a $10^{8}$ esporos $/ \mathrm{ml}$, atingindo o máximo (100\%) na concentração de $10^{4}$ esporos/ml para $F$. verticillioides e $R$. stolonifer, enquanto o mesmo nível foi atingido por $G$. candidum com $10^{8}$ esporos/ml (Figura 3 ).

Foram constatadas diferenças significativas $(\mathrm{P}=0,05)$ nos valores de incidência das doenças entre os fungos para as diferentes concentrações de inóculo, não sendo verificada interação significativa $(\mathrm{P}=0,05)$ entre fungos e concentrações de inóculo.

As curvas de progresso da incidência das podridões, em função das concentrações de inóculo, tiveram um excelente ajuste pelo modelo não linear Logístico Dose-Resposta $y=$ $a+b /\left(1+(x / c)^{d}\right)$, com coeficientes de determinação de 99,90 (G. candidum) e $99,99 \%$ ( $F$. verticillioides e $R$. stolonifer) (Figura 3).

\section{DISCUSSÃO}

Os resultados deste estudo demonstram a influência variável da temperatura, do período de molhamento e da concentração de inóculo na incidência de podridões póscolheita em frutos de tomateiro causadas por $F$. verticillioides, G. candidum e R. stolonifer.

A maior incidência de podridões em frutos de tomateiro incubados a $25{ }^{\circ} \mathrm{C}$ assemelha-se à relatada para doenças póscolheita causadas por Fusarium spp., G. candidum e $R$. stolonifer em outros hospedeiros (Smith \& McClure, 1960; Sommer et al., 1992; Rezende \& Fancelli, 1997). Em relação a doenças pós-colheita em tomateiro, Moline (1984) obteve resultados similares quando inoculou $G$. candidum em frutos maduros, enquanto Arinze (1986) e Olandiran \& Iwu (1993) verificaram que as temperaturas ótimas para uma maior taxa de progresso de podridões causadas por Fusarium spp. e $G$. candidum situavam-se entre 30 e $35^{\circ} \mathrm{C}$.

A ausência de lesões em frutos de tomateiro inoculados 
com outras espécies de Fusarium e mantidos a $5^{\circ} \mathrm{C}$ também foi constatada por Arinze (1986) e Olandiran \& Iwu (1993). De forma similar, a reduzida incidência de podridão em frutos de tomateiro inoculados com G. candidum e mantidos a $5^{\circ} \mathrm{C}$ assemelha-se à verificada por Moline (1984). Embora a baixa temperatura reduza a respiração do fruto e reações enzimáticas que podem causar deterioração e favorecer a atividade microbiana (Arinze, 1986), a exposição dos frutos a baixas temperaturas durante um certo período de tempo pode não afetar a germinação de esporos ou a subseqüiente penetração dos frutos, conforme foi verificado por Smith \& McClure (1960) em estudos realizados com $R$. stolonifer em frutos de pessegueiro [Prunus persica (L.) Batsch.]. Dessa forma, o desenvolvimento de lesões poderá ocorrer se os níveis de temperatura retornarem às condições favoráveis à atividade do patógeno. Além disso, o armazenamento prolongado de frutos de tomateiro a temperaturas inferiores a $10^{\circ} \mathrm{C}$ provoca danos fisiológicos pelo resfriamento, sob a forma de enfraquecimento dos tecidos e manchas (Olandiran \& Iwu, 1993; Bleinroth, 1995).

A incidência elevada de podridão em frutos de tomateiro inoculados com $R$. stolonifer e incubados a $5{ }^{\circ} \mathrm{C}$, verificada neste estudo, confronta-se com as observações de Arinze (1986), que não constatou a presença de lesões em frutos dessa solanácea quando inoculados com o patógeno e incubados à mesma temperatura. Tanaka et al. (1997) também relataram que a temperatura é limitante para o progresso de podridão causada por $R$. stolonifer em frutos de morangueiro (Frajaria ananassa Duch.), uma vez que, abaixo de $6{ }^{\circ} \mathrm{C}$, não ocorre a germinação dos esporos e a produção de esporângios é inibida por temperaturas inferiores a $8{ }^{\circ} \mathrm{C}$. As diferenças verificadas nesse trabalho podem estar relacionadas com a adaptação de alguns isolados às condições de armazenamento, pois, conforme foi sugerido por Gunderson (1961), alguns patógenos pós-colheita possuem grande capacidade de crescimento em baixas temperaturas.

Embora a umidade afete a formação, longevidade e principalmente a germinação de esporos fúngicos, que requerem um filme de água cobrindo os tecidos ou alta umidade relativa na atmosfera, o surgimento de podridões causadas por $F$. verticillioides, $G$. candidum e $R$. stolonifer na ausência de água livre na superfície dos frutos de tomateiro indica que apenas a água liberada após a realização do ferimento é suficiente para o estabelecimento do processo de infecção. Por outro lado, o aumento dos níveis de incidência das podridões com a elevação do período de molhamento confirma a importância da umidade elevada no progresso de podridões, sugerindo que a pulverização dos frutos com água, procedimento muito freqüente durante a comercialização de tomate em feiras livres, constitui uma prática que poderá aumentar o período de molhamento e, conseqüentemente, os níveis de incidência de podridões causados por $F$. verticillioides e G. candidum. Em relação a $R$. stolonifer, a elevada incidência de podridões na ausência de molhamento difere das observações de Bleicher (1997) e Smith \& McClure (1960), que no caso de rosáceas de caroço, consideram
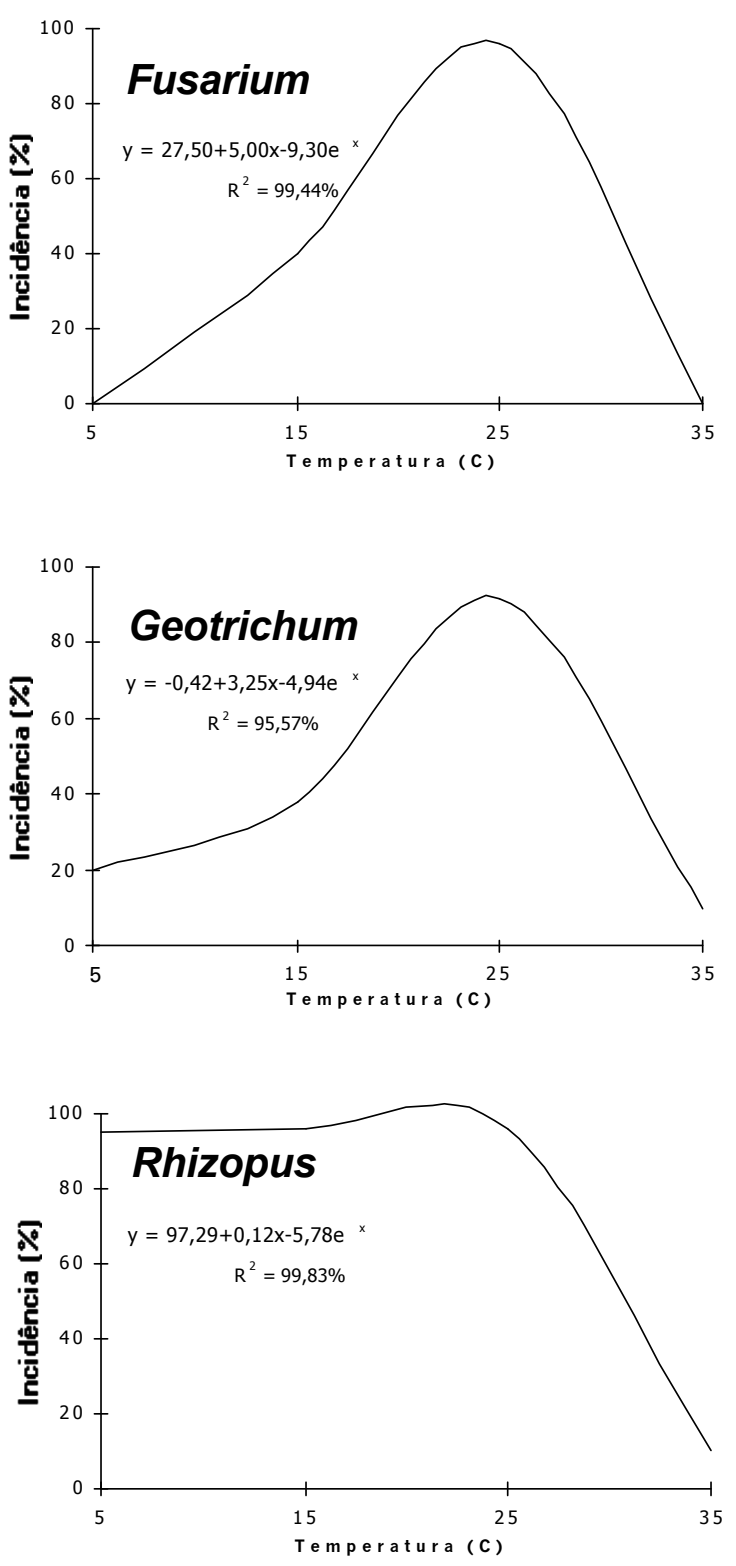

FIG. 1 - Influência da temperatura na incidência de podridões em frutos de tomateiro (Lycopersicon esculentum) causadas por Fusarium verticillioides, Geotrichum candidum e Rhizopus stolonifer.

indispensável a presença de alta umidade para a infecção dos frutos por esse patógeno.

O manejo da umidade constitui importante estratégia na redução da deterioração fisiológica, na prevenção da perda de umidade e no conseqüente murchamento dos frutos de tomate durante o armazenamento e comercialização (Bleinroth, 1995). Nesse contexto, Arinze (1986) e Olandiran \& Iwu (1993) consideram que a umidade apresenta-se como um fator mais relevante na manutenção da qualidade de frutos frescos de tomateiro do que a deterioração causada por microrganismos. 
Influência da temperatura, período de molhamento e concentração do inóculo...
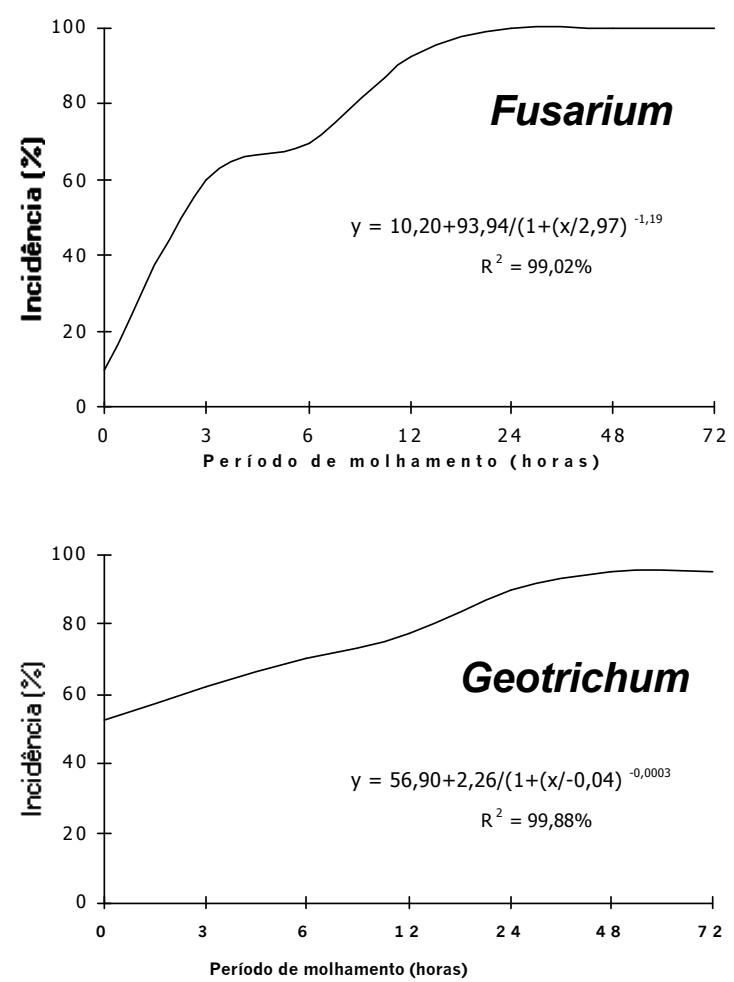

FIG. 2 - Influência do período de molhamento na incidência (\%) de podridões em frutos de tomateiro (Lycopersicon esculentum) causadas por Fusarium verticillioides e Geotrichum candidum.

A incidência de podridões em frutos de tomateiro, mesmo com concentrações de inóculo muito baixas, indica a elevada viabilidade dos esporos de $F$. verticillioides, $G$. candidum e R. stolonifer. A maior agressividade dos isolados de $F$. verticillioides e $R$. stolonifer ficou evidenciada quando o nível máximo de doença foi atingido com uma menor concentração de inóculo, comparado ao nível de G. candidum, sugerindo que esse patógeno necessita de uma quantidade maior de propágulos para o progresso rápido da doença. Segundo Johnson \& Sangchote (1994), fungos que causam doenças em frutos tropicais geralmente não apresentam seletividade em relação a hospedeiros, entretanto, entre os fatores envolvidos na diferenciação destes, está incluída a disponibilidade de inóculo, sendo o conhecimento da influência desse componente no patossistema um fator importante para o sucesso do controle dessas doenças.

As equações resultantes da análise do progresso da incidência das podridões em função da temperatura, do período de molhamento e da concentração do inóculo de $F$. verticillioides, G. candidum e $R$. stolonifer permitem estimativas da incidência de doenças em frutos de tomateiro com elevados níveis de precisão quando essas variáveis são consideradas.

No conjunto dos resultados, os níveis de incidência das podridões causadas por $F$. verticillioides e $G$. candidum
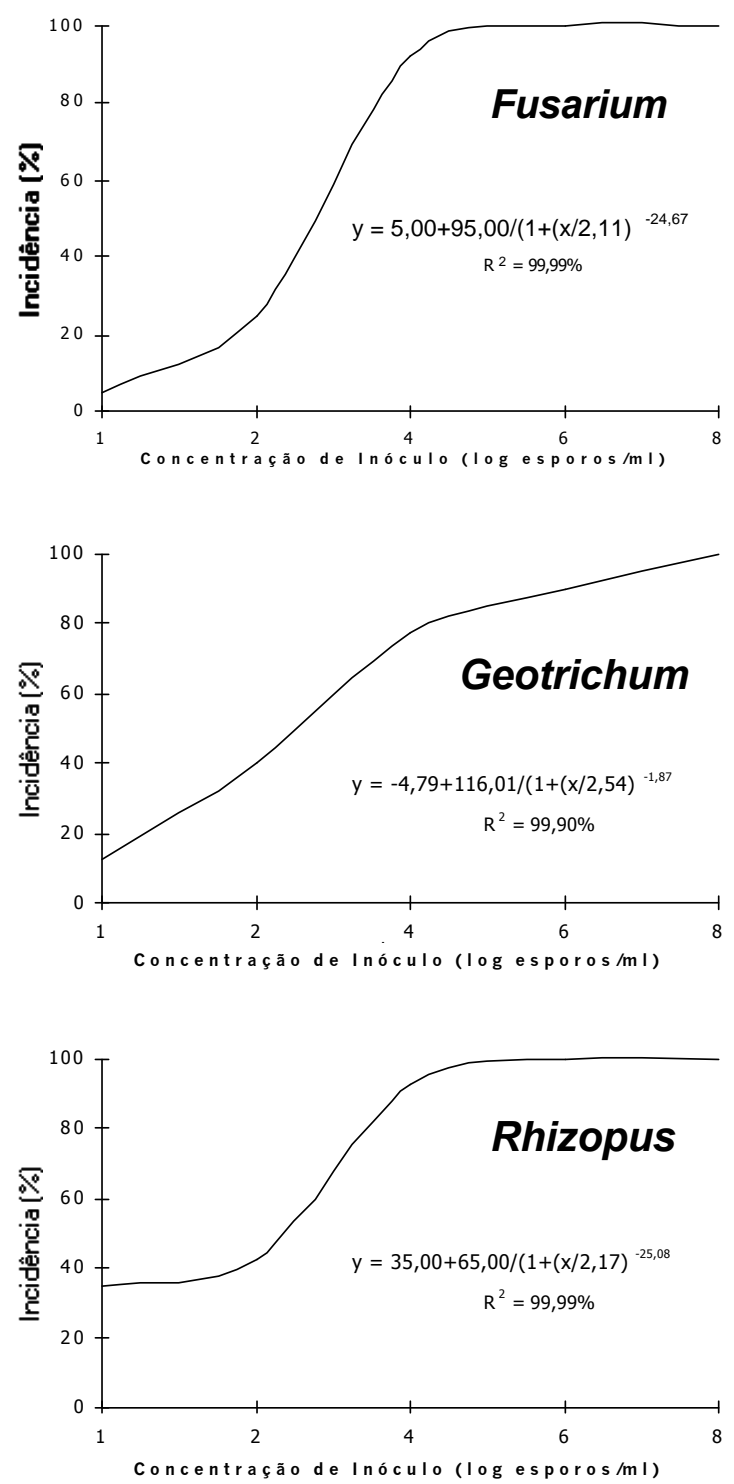

FIG. 3 - Influência da concentração de inóculo de Fusarium verticillioides, Geotrichum candidum e Rhizopus stolonifer na incidência de podridões em frutos de tomateiro (Lycopersicon esculentum).

foram influenciados significativamente pela temperatura, pelo período de molhamento e pela concentração de inóculo, enquanto somente esta última variável teve influência sobre o nível de doença causada por $R$. stolonifer. Práticas de manejo que envolvam o controle das variáveis ambientais, tais como evitar a exposição dos frutos a temperaturas ideais para os patógenos e umidade elevada, bem como evitar ferimentos nos frutos durante a colheita, transporte e armazenamento, e utilizar caixas novas ou eficientemente desinfestadas, constituem medidas importantes para reduzir a influência da temperatura e da umidade no desenvolvimento das podridões e diminuir o número de propágulos viáveis dos patógenos causadores dessas podridões no ambiente de póscolheita. 


\section{REFERÊNCIAS BIBLIOGRÁFICAS}

AGRIOS, G.N. Plant Pathology. $4^{\text {th }}$ ed. San Diego. Academic Press. 1997.

ARINZE, A.E. Post-harvest diseases of tomato fruits in Southern Nigeria. Fitopatologia Brasileira 11:637-645. 1986.

BLEICHER, J. Doenças de rosáceas de caroço (pessegueiro, ameixeira, nespereira). In: KIMATI, H., AMORIM, L., BERGAMIN FILHO, A., CAMARGO, L.E.A. \& REZENDe, J.A.M. (Eds.) Manual de Fitopatologia: Doenças das Plantas Cultivadas. 3. ed. São Paulo. Agronômica Ceres. 1997. v.2, pp.621-627.

BLEINROTH, E.W. Características dos frutos de exportação. In: GAYET, J.P., BLEINROTH, E.W., MATALLO, M., GARCIA, E.E.C., ARDITO, E.F.G. \& BORDIN, M.R. (Eds.) Tomate para Exportação: Procedimentos de Colheita e Pós-colheita. Brasília. EMBRAPA-SPI. 1995. pp.9-20.

CEPONIS, M.J. \& BUTTERFIELD, L.E. Losses in fresh tomatoes at the retail and consumer levels in greater New York area. Journal of the Amercican Society of Horticultural Science 104:751-754. 1979.

CEPONIS M.J., CAPPELLINI, R.A. \& LIGHTNER, G.W. Disorders in tomato shipments to the New York market, 1972-1984. Plant Disease 70:261-264. 1986.

DILLARD, H.R. Effect of temperature, wetness duration, and inoculum density on infection and lesion development of Colletotrichum coccodes on tomato fruit. Phytopathology 79:1063-1066. 1989.

EDEN, M.A., HILL, R.A., BERESFORD, R. \& STEWART, A. The influence of inoculum concentration, relative humidity and temperature on infection of greenhouse tomatoes by Botrytis cinerea. Plant Pathology 45:795806. 1996.

GUNDERSON, M.F. Mold problem in frozen foods. In: Proceedings, The Low Temperature Microbiol Symposium, New Jersey, USA, Campbell Soup Co. 1961. pp.299-312,

JONHSON, G.I. \& SANGCHOTE, S. Control of postharvest diseases of tropical fruits: Challenges for the 21st century. In: CHAMP, B.R., HIGHLEY, E. \& JOHNSON, G.I. (Eds.) Postharvest Handling of Tropical Fruits. Canberra. ACIAR. 1994. pp.140-161.

LOPES, C.A. \& SANTOS, J.R.M. Doenças do Tomateiro. Brasília. EMBRAPA-SPI. 1994.

MOLINE, H.E. Diagnosis of postharvest diseases and disorders. In: MOLINE, H.E. (Ed.) Postharvest
Pathology of Fruits and Vegetables: Postharvest Losses in Perishable Crops. Berkeley. University of California Agricultural Experiment Station. 1984. pp.17-23.

O'BRIEN, R.G., PERSLEY, D.M., THOMAS, J.E. \& DULLAHIDE, S.R. Tomato. In: PERSLEY, D.M. (Ed.) Diseases of Vegetable Crops. Brisbane. Queensland Department of Primary Industries. 1994. pp.88-100.

OLANDIRAN, A.O. \& IWU, L.N. Studies on the fungi associated with tomato rots and effects of environment on storage. Mycopathology 121:157-161. 1993.

ONESIROSAN, P.T. \& FATUNLA, T Fungal fruit rots of tomatoes in southern Nigeria. Journal of Horticultural Science 51:473-179. 1979.

PRATT, H.K. \& WORKMAN, M. Studies on the physiology of tomato fruits III. The effects of ethylene on respiration and ripening behaviour of fruits stored at $20^{\circ} \mathrm{C}$ after harvest. Proceedings of the American Society of Horticultural Sciences 81:467-478. 1962.

REZENDE, J.A.M. \& FANCELLI, M.I. Doenças do mamoeiro (Carica papaya L.). In: KIMATI, H., AMORIM, L., BERGAMIN FILHO, A., CAMARGO, L.E.A. \& REZENDE, J.A.M. (Eds.) Manual de Fitopatologia: Doenças das Plantas Cultivadas. 3. ed. São Paulo. Agronômica Ceres. 1997. v.2, pp. 486-496.

SILVEIRA, N.S.S., MARIANO, R.L.R. \& OLIVEIRA, S.M.A. Fungos fitopatogênicos associados com frutos comercializados na cidade do Recife - PE. Fitopatologia Brasileira 23:297. 1998.

SMITH, JR. W.L. \& MCCLURE, T.T. Rhizopus rot of peaches as affected by postharvest temperature and moisture. Phytopathology 50:558-562. 1960.

SOMMER, N. F., FORTLAGE, R.J. \& EDWARDS, D.C. Postharvest diseases of selected commodities. In: KADER, A.A. (Ed.) Postharvest Technology of Horticultural Crops. $2^{\text {nd }}$ ed. Berkeley. University of California. 1992. pp.117-160.

SANOGO, S., PENNYPACKER, S.P., STEVENSON, S.P. \& MACNAB, A.A. Weather variables associated with infection of tomato fruit by Colletotrichum coccodes. Plant Disease 81:753-756. 1997.

TANAKA, M.A.S., BETTI, J.A. \& KIMATI, H. Doenças do morangueiro (Fragaria ananassa Duch.). In: KIMATI, H., AMORIM, L., BERGAMIN FILHO, A., CAMARGO, L.E.A. \& REZENDE, J.A.M. (Eds.) Manual de Fitopatologia: Doenças das Plantas Cultivadas. 3. ed. São Paulo. Agronômica Ceres. 1997. v.2, pp.556-571. 